\title{
Resveratrol inhibits oxygen-glucose deprivation-induced MMP-3 expression and cell apoptosis in primary cortical cells via the NF-кB pathway
}

\author{
TAO HUANG, DAKUAN GAO, XIAOFAN JIANG, SHIJIE HU, LEI ZHANG and ZHOU FEI \\ Department of Neurosurgery, Xijing Hospital, Fourth Military Medical University, Xi'an, Shaanxi 710032, P.R. China
}

Received October 13, 2013; Accepted March 18, 2014

DOI: $10.3892 / \mathrm{mmr} .2014 .2239$

\begin{abstract}
Resveratrol (Res) or trans-3,4',5-trihydroxystilbene, has been proven to exert neuroprotective effects in cerebral ischemia. The aim of the present study was to investigate whether Res has neuroprotective effects in primary cortical neurons subjected to transient oxygen-glucose deprivation (OGD) via inhibiting the expression of the gene encoding stromelysin-1, also known as matrix metalloproteinase-3 (MMP-3), and via inhibiting cell apoptosis. Primary cortical cells were exposed to OGD, followed by reoxygenation to induce transient ischemia. Res $(50 \mu \mathrm{M})$ was added into the culture medium during transient ischemia in the presence or absence of the nuclear factor (NF)- $\mathrm{\kappa B}$ inhibitor pyrrolidine dithiocarbamate (PDTC; $10 \mu \mathrm{M}$ ) or $500 \mu \mathrm{M}$ of the nitric oxide (NO) donor NOC-18. Cell viability was assessed using the tetrazolium reduction (MTT) assay. Cell apoptosis was evaluated by flow cytometry. MMP-3 expression was analyzed by western blot and reverse transcription-polymerase chain reaction (RT-PCR), while the levels of inducible NO synthase (iNOS), NF- $\kappa$ B, caspase-3, cleaved caspase-3, B-cell lymphoma 2 (Bcl-2) and Bcl-2-associated X protein (Bax) were assayed by western blot. NO was detected using a spectrophotometric method. We found that the cellular viability was significantly reduced by transient OGD and that this effect was reversed by Res treatment. In addition, OGD was shown to induce cell apoptosis, the expression of Bax and the activation of caspase-3, and inhibit the expression of Bcl-2, and these effects were also reversed by Res treatment. Res treatment significantly reduced the level of MMP-3 that was induced by transient OGD, via inhibition of NF- $\mathrm{\kappa B}$ expression. In addition, Res inhibited iNOS expression and NO
\end{abstract}

Correspondence to: Professor Dakuan Gao or Professor Zhou Fei, Department of Neurosurgery, Xijing Hospital, Fourth Military Medical University, 15 Changle West Road, Xi'an, Shaanxi 710032, P.R. China

E-mail: dakgao@fmmu.edu.cn

E-mail: zhoufeishaanxi@163.com

Key words: resveratrol, cortical cells, oxygen-glucose deprivation, MMP-3, nuclear factor- $\kappa \mathrm{B}$, inducible nitric oxide synthase, nitric oxide, apoptosis synthesis that were induced by OGD. MMP-3 expression induced by $\mathrm{NO}$ was attenuated by Res treatment and was partially restored by exogenous NO using NOC-18. Taken together, these findings indicate that OGD induces apoptosis through canonical apoptosis signaling and by modulating the expression of MMP-3; Res can reverse the OGD-induced MMP-3 expression and cell apoptosis via the NF- $\mathrm{kB}-\mathrm{iNOS} /$ NO pathway. Therefore, Res may be a promising agent for the treatment of neuronal injury associated with stroke.

\section{Introduction}

The brain is the most vulnerable organ to ischemic infringement. Cerebral ischemia reperfusion injury is a recognized complication of restoring blood flow in the ischemic brain tissue (1). During brain ischemia and reperfusion injury neurons undergo apoptosis $(2,3)$. Various mechanisms have been proposed for the pathophysiology of cerebral ischemia-reperfusion injury, including glutamate release, ATP depletion, anoxic depolarization, the generation of reactive oxygen and nitrogen species, inflammatory cytokines, and matrix metalloproteinases (MMPs) (4-7).

Matrix metalloproteinase (MMP)-3 is involved in neuroinflammation $(8,9)$, cell apoptosis (10), extracellular matrix (ECM) degradation (11), and the cleavage and activation of other MMPs, as well as shedding of death receptors $(12,13)$. It is rapidly upregulated upon cerebral ischemia in rats, mice, and primates including humans (14). There is evidence that MMP-3 is involved in blood brain barrier (BBB) breakdown and neuronal death $(9,15)$, while it was also implicated in microglial activation and inflammation in a Parkinson's disease model (16). Since MMP-3 participates in apoptotic signaling, the latter may be reversed by pharmacological inhibition, gene knockdown and gene knockout of MMP-3 in vitro $(17,18)$. It was reported that MMP-3 is regulated by the nuclear factor (NF)- $\mathrm{B}$ (19).

Resveratrol (Res) or trans-3,4',5-trihydroxystilbene, is a natural phytoalexin found in plants that has neuroprotective, anticancer and anti-inflammatory effects (20-22). Res was also reported to have anti-oxidant properties, for example the ability to modulate nitric oxide (NO) metabolism (23), chemopreventive activity (24), and the ability to regulate the expression of MMP-3 (19). Res also exerted protective effects against brain injury induced by ischemia-reperfusion 
in gerbils (25). The beneficial neuroprotective effects of Res may be due to its antiplatelet aggregation and vasodilating effect, its antioxidant activity or the combination of the above. Our previous study demonstrated that cerebral ischemiareperfusion injury induces the expression of MMP-9 in mice (26). However, whether Res can act as a MMP-3 inhibitor in cerebral ischemia remains unknown.

In this context, the present study investigated the effects of Res on injury induced by oxygen-glucose deprivation (OGD), as well as the underlying mechanism, in primary cortical neuron cultures.

\section{Materials and methods}

Preparation of mouse cortical cultures. All procedures used in this study complied with the Guide for the Care and Use of Laboratory Animals of the Xijing Hospital. Cultures of mouse cortical neurons were prepared using methods similar to those previously reported (27). Timed-pregnant (13-15 days) $\mathrm{Balb} / \mathrm{C}$ mice were anesthetized with halothane and sacrificed by cervical dislocation. After dissection, cortical neurons were dispersed by trituration and digestion in $0.25 \%$ trypsin (Sigma-Aldrich, St. Louis, MO, USA) for $30 \mathrm{~min}$ at $37^{\circ} \mathrm{C}$. Then, the cell suspension was centrifuged at $4^{\circ} \mathrm{C}$ for $5 \mathrm{~min}$ at $250 \mathrm{~g}$, and resuspended in dissociating medium [Dulbecco's modified Eagle's medium (DMEM) supplemented with $10 \%$ fetal bovine serum (Gibco-BRL, Carlsbad, CA, USA), $2 \mathrm{mM}$ L-glutamine, $10 \mathrm{mM}$ HEPES and $44 \mathrm{mM}$ glucose (all from Sigma-Aldrich)]. Cells were plated on poly-L-lysine-coated culture plates at a density of $1 \times 10^{6}$ cells $/ \mathrm{ml}$. Twenty-four hours later, the medium was replaced by Neurobasal medium consisting of $2 \% \mathrm{~B} 27{ }^{\circledR}$ Supplement, $0.5 \mathrm{mM}$ L-glutamine, and $25 \mu \mathrm{M}$ glutamate (all from Sigma-Aldrich) to minimize glial growth. At 7 days of growth, one-half of the medium was replaced with new Neurobasal medium. Experiments were performed on cultures following 14-16 days of incubation.

Simulation of ischemia and reperfusion injury in vitro. OGD was used as an in vitro model of ischemia. For OGD, the medium was removed and stored separately. Cultures were rinsed three times with phosphate-buffered saline (PBS), and low-glucose DMEM with $2 \%$ B27 ${ }^{\circledR}$ Supplement was added. Cultures were then transferred to a humidified chamber kept in a $37^{\circ} \mathrm{C}$ incubator and subjected to an anaerobic environment of $95 \% \mathrm{~N}_{2}-5 \% \mathrm{CO}_{2}$ for $3 \mathrm{~h}$. Oxygen concentration was maintained at $0.5-1.0 \%$, which was monitored by an oxygen analyzer (MSA, Pittsburgh, PA, USA), throughout the experiment. OGD was terminated by the replacement of stored medium and by returning the cultures to a standard incubator maintained at $37^{\circ} \mathrm{C}$ in a $5 \% \mathrm{CO}_{2}$ atmosphere for $21 \mathrm{~h}$ of reoxygenation. Control cells were not subjected to OGD and were grown at $37^{\circ} \mathrm{C}$ in an atmosphere containing $5 \% \mathrm{CO}_{2}$.

Treatment with Res. A fresh solution of Res was prepared from a stock of $100 \mathrm{mM}$ Res in 50\% dimethylsulfoxide (DMSO) (both from Sigma-Aldrich), and was diluted in PBS to reach the desired final concentration $(10,25,50$ and $100 \mu \mathrm{M})$ for treatment. Res treatment controls (vehicle group) received the same amount of DMSO without Res. The duration of treatment was from OGD until the end of the experiment.
Treatment with inhibitors. Pyrrolidine dithiocarbamate (PDTC) is a specific NF- $\mathrm{BB}$ inhibitor. PDTC $(10 \mu \mathrm{M}$; Sigma-Aldrich) was added 15 min prior to Res treatment. Next, Res was added to cultures at a final concentration of $50 \mu \mathrm{M}$. The vehicle group cultures received the same amount of the carrier solvent $(0.1 \%$ DMSO) without Res. The duration of the treatment was from OGD until the end of the experiment.

Treatment with NO donor. NOC-18 (Dojindo Molecular Technologies, Inc., Kumamoto, Japan) is a diazeniumdiolate (NONOate) $\mathrm{NO}$ donor designed to release $\mathrm{NO}$ at a slower rate. NOC-18 $(500 \mu \mathrm{M})$ was added during Res treatment.

Cell viability assay. The effects of Res on OGD-induced cytotoxicity were examined by the 3-(4,5-dimethylthiazol2-yl)-2,5-diphenyltetrazolium bromide (MTT) uptake assay, with a commercial kit purchased from Sigma-Aldrich. Neuronal primary cultures were grown on 96-well plates at a density of $2 \times 10^{5}$ cells $/ \mathrm{cm}^{2}$. At 14 days of growth, cells were subjected to OGD and reoxygenation. Different concentrations of Res were added to the medium. After $21 \mathrm{~h}$ of reoxygenation, MTT was added to the cells at a final concentration of $0.5 \mathrm{mg} /$ $\mathrm{ml}$, and the plates were incubated for $4 \mathrm{~h}$ at $37^{\circ} \mathrm{C}$. The insoluble formazan product was then precipitated by centrifugation, the supernatant removed, and the crystals were dissolved in $100 \mu \mathrm{l}$ DMSO. Absorbance at $570 \mathrm{~nm}$ was measured using a microplate reader (Bio-Rad, Hercules, CA, USA). The ratio of absorbance of treated cells to that of the control cells was calculated, and was used to represent the percentage of growth inhibition.

Apoptosis assay. Cell apoptosis was assayed by flow cytometry with the Annexin V-FITC Apoptosis Detection kit (Sigma-Aldrich). Cells were subjected to OGD and reoxygenation, and different concentrations of Res were added to the medium. Specifically, $1 \times 10^{6}$ single cells per sample were collected following a 3-h OGD, were reoxygenated for $21 \mathrm{~h}$ and were washed twice with PBS buffer; Annexin V/FITC was then added. After incubation for $10 \mathrm{~min}$ at room temperature in the dark, the cells were washed and resuspended; propidium iodide was then added to a final concentration of $1 \mathrm{mg} / 1$. Stained cells were analyzed using a FACSCalibur instrument (Becton Dickinson, Mountain View, CA, USA).

Reverse transcription-polymerase chain reaction (RT-PCR). The level of $M M P-3$ mRNA was semi-quantified using RT-PCR. Total RNA was extracted using the TRIzol reagent (Invitrogen Life Technologies, Carlsbad, CA, USA), and dissolved in nuclease-free water, according to the manufacturer's instructions. Reverse transcription was performed with oligo(dT) primers and the First-Strand cDNA Synthesis kit (Invitrogen Life Technologies). The synthesized first-strand cDNA $(1 \mu \mathrm{l})$ was next subjected to PCR amplification using the following program: $94^{\circ} \mathrm{C}$ for $30 \mathrm{sec} ; 56^{\circ} \mathrm{C}$ for $1 \mathrm{~min} ; 72^{\circ} \mathrm{C}$ for $1 \mathrm{~min}$. A total of 35 cycles were performed for the amplification of $M M P-3$ and 30 cycles for the housekeeping gene $\beta$-actin, which served as the control. The last cycle was followed by $10 \mathrm{~min}$ of elongation at $72^{\circ} \mathrm{C}$. Primer pairs for the amplification of the mouse $M M P-3$ and $\beta$-actin genes (231 and $242 \mathrm{bp}$, respectively) were the following: MMP-3 forward, 
5'-GTACCA ACCTATTCCTGGTTGC-3', and reverse, 5'-CCAGAGAGT TAGATTTGGTGGG-3'; $\beta$-actin forward, 5'-AACCCTAAG GCCAACCGTGAAAAG-3', and reverse, 5'-TCATGAGGT AGTCTGTCAGGT-3'. PCR products were visualized on $1.5 \%$ agarose gels stained with ethidium bromide ausing a UV Transilluminator 2000 (\#170-7942; Bio-Rad). Semi-quantitative analysis was conducted using a computerized densitometric imager (Gel Doc ${ }^{\mathrm{TM}} \mathrm{XR}+$, Bio-Rad).

Western blot analysis. Protein concentrations were determined using the Bradford assay (Bio-Rad). The same amount of total proteins ( $30 \mu \mathrm{g} / \mathrm{lane}$ ) was loaded into each lane, electrophoresed and transferred onto nitrocellulose membranes at $80 \mathrm{~V}$ for $1 \mathrm{~h}$. After blocking for $4 \mathrm{~h}$ in $5 \%$ skim milk, the membrane was incubated overnight at $4^{\circ} \mathrm{C}$ with primary antibodies (dilution, 1:1,000) targeting MMP-3, inducible NO synthase (iNOS), NF- $\kappa B, \beta$-actin, B-cell lymphoma 2 (Bcl-2), Bcl-2-associated X protein (Bax) (all from Sigma-Aldrich), and caspase-3 (monoclonal antibody; Cell Signaling Technology, Inc., Danvers, MA, USA). Next, the membrane was incubated with the corresponding secondary antibody (goat anti-rat IgG; diluted with PBS at 1:1,000; Sigma-Aldrich) at room temperature for $1 \mathrm{~h}$. Finally, the proteins were detected using the standard enhanced chemiluminescence ECL method using a kit purchased from Santa Cruz Biotechnology, Inc. (Santa Cruz, CA, USA).

Intracellular NO measurement. NO levels were estimated with the Griess assay. We used the Griess Reagent system (Promega Corp., Madison, WI, USA) and measured the total nitrate and nitrite concentrations at $550 \mathrm{~nm}$ in a SmartSpec Plus Spectrophotometer (\#170-2525; Bio-Rad).

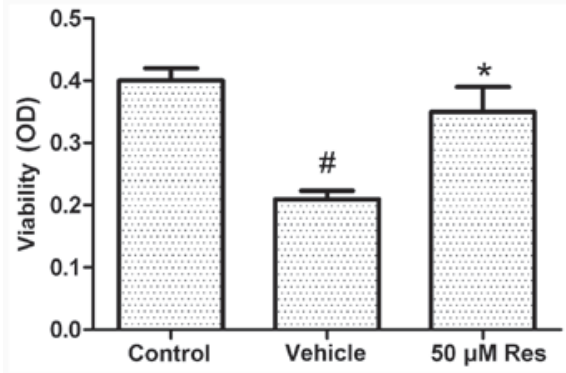

Figure 1. MTT cell viability assay shows that treatment with $50 \mu \mathrm{M}$ resveratrol (Res) significantly protects primary cortical neuron cultures against transient oxygen-glucose deprivation (OGD). Cell viability is expressed as optical density (OD) of each group (10 wells/group) at $570 \mathrm{~nm} .{ }^{\#} \mathrm{P}<0.05 \mathrm{vs}$. control (no OGD); ${ }^{*} \mathrm{P}<0.05$ vs. vehicle (OGD + dimethylsulfoxide).

Data analysis. Unless otherwise stated, all experiments were performed with triplicate samples and repeated at least three times. Results were presented as the means \pm SD. Statistical comparisons between groups were performed using one-way ANOVA followed by Student's t-tests. $\mathrm{P}<0.05$ or $<0.01$ was considered to indicate a statistically significant difference.

\section{Results}

Cell viability assay. The MTT assay was used to analyze the viability of cells. In this assay, the number of viable cells is directly proportional to the level of the produced formazan product. Our preliminary experiments demonstrated that treatment with $50 \mu \mathrm{M}$ Res exerted therapeutic effects. Exposure of the cells to OGD for $3 \mathrm{~h}$ followed by $21 \mathrm{~h}$ of reoxygenation caused a reduction in cell viability of $\sim 45 \%$.
A

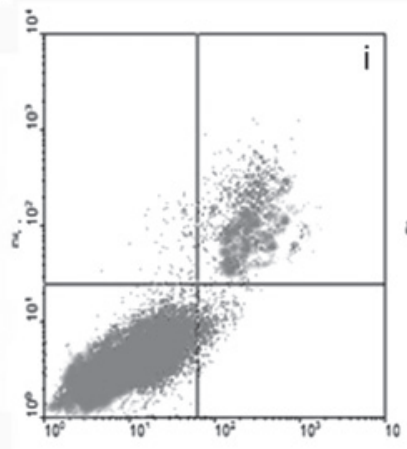

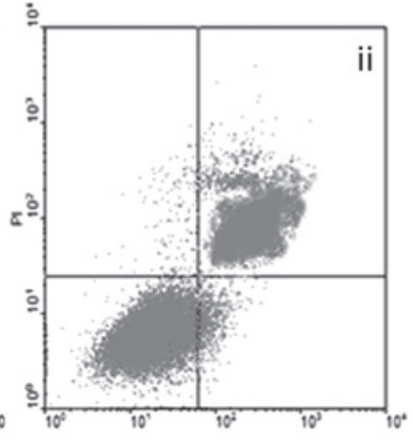

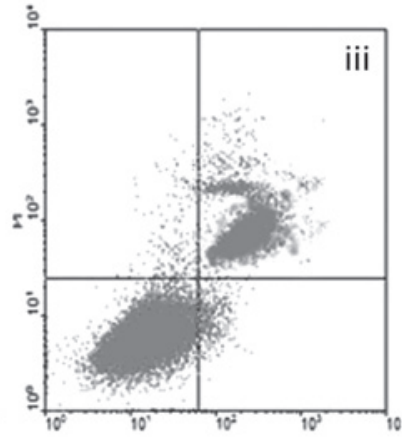

B

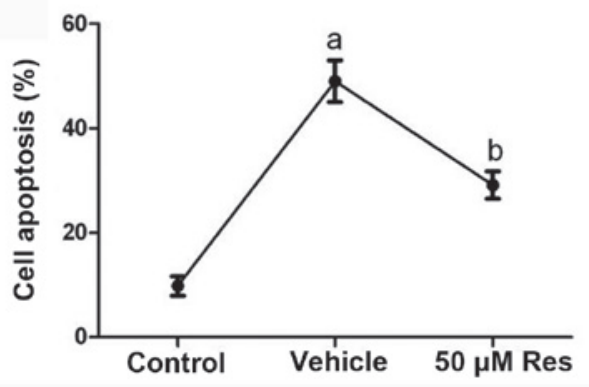

Figure 2. Effect of resveratrol (Res) on oxygen-glucose deprivation (OGD)-induced apoptosis in cortical neuron cultures measured by flow cytometry. (A) Scatterplots of apoptosis in the (i) control (no OGD), (ii) vehicle (OGD + DMSO) and (iii) OGD $+50 \mu \mathrm{M}$ Res groups. (B) Cell apoptosis rate $\pm \mathrm{SD}$, $\mathrm{n}=5$. ${ }^{\mathrm{a} P}<0.05$ vs. control (no OGD); ${ }^{\mathrm{b}} \mathrm{P}<0.05$ vs. vehicle (OGD + dimethylsulfoxide). 

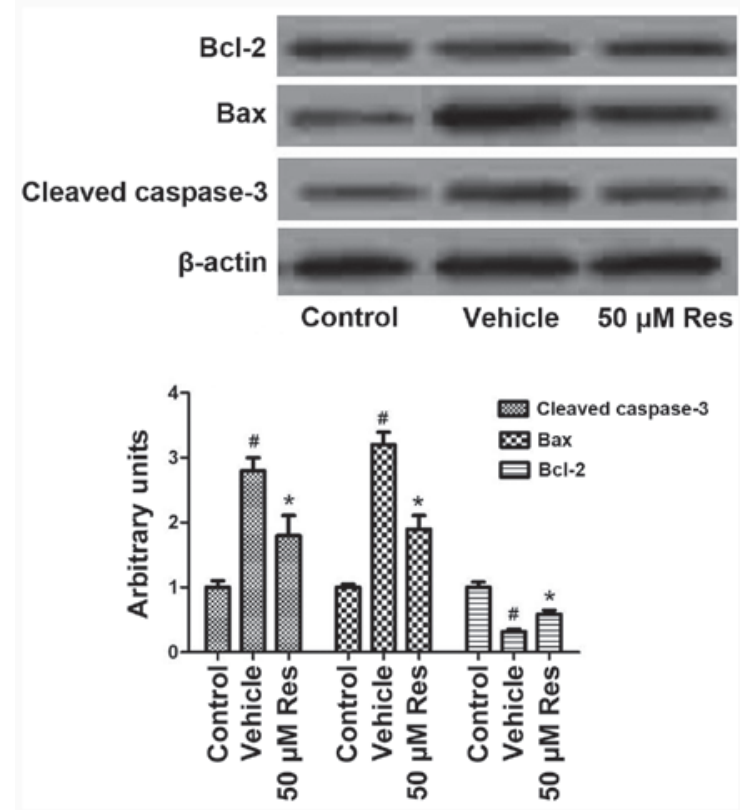

Figure 3. Effect of resveratrol (Res) on oxygen-glucose deprivation (OGD)-induced apoptotic signaling. The levels of B-cell lymphoma 2 (Bcl-2), caspase-3, the cleaved form of caspase-3 and Bcl-2-associated $\mathrm{X}$ protein (Bax) were determined using western blotting with corresponding antibodies. $\beta$-actin was used as the loading control. Each blot is representative of three independent experiments. ${ }^{~} \mathrm{P}<0.05$ vs. control (no OGD); ${ }^{*} \mathrm{P}<0.05$ vs. vehicle (OGD + dimethylsulfoxide).

Under these conditions, pretreatment with Res $(50 \mu \mathrm{M})$ increased cell viability (as opposed to OGD-induced cell death) by $75 \%$ (Fig. 1).

Res inhibits $O G D$-induced cell apoptosis. Flow cytometry was used to quantify neuronal apoptosis induced by OGD. As shown in Fig. 2, in the control (no OGD) cells, there was a very low level (9.8\%) of neuronal apoptosis, but the
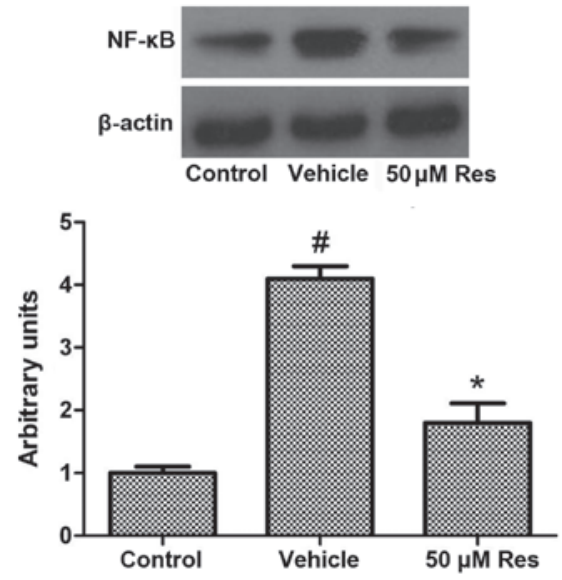

Figure 4. The oxygen-glucose deprivation (OGD)-induced expression of nuclear factor (NF)- $\mathrm{\kappa B}$ is inhibited by resveratrol (Res). ${ }^{~} \mathrm{P}<0.05$ vs. control (no OGD); $\mathrm{P}<0.05$ vs. vehicle (OGD + dimethylsulfoxide).

percentage of apoptosis was significantly increased to $49 \%$ $(\mathrm{P}<0.01)$ upon OGD, and was reversed to $29.1 \%$ when $50 \mu \mathrm{M}$ of Res were applied during OGD $(\mathrm{P}<0.05)$. The vehicle solution (DMSO) had no effect on cell apoptosis induced by OGD $(\mathrm{P}>0.05)$.

Res induces the expression of anti-apoptotic and inhibits the expression of pro-apoptotic proteins. To gain insights into the mechanisms by which Res attenuates OGD-induced cell apoptosis, we studied the expression of pro- and anti-apoptotic proteins following OGD and Res treatment. As shown in Fig. 3, OGD induced the cleavage of the pro-apoptotic protein caspase-3, and this effect was reversed by treatment with $50 \mu \mathrm{M}$ Res $(\mathrm{P}<0.05)$; similarly, OGD-induced Bax expression was also reduced by Res. By contrast, the expression of the anti-apoptotic protein $\mathrm{Bcl}-2$ was reduced by OGD, and this effect was reversed by Res treatment. These results suggest

A

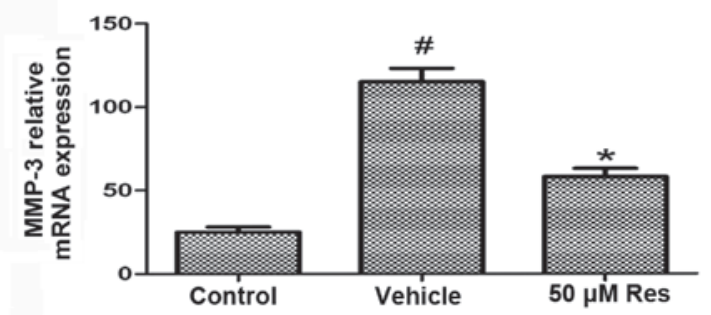

B
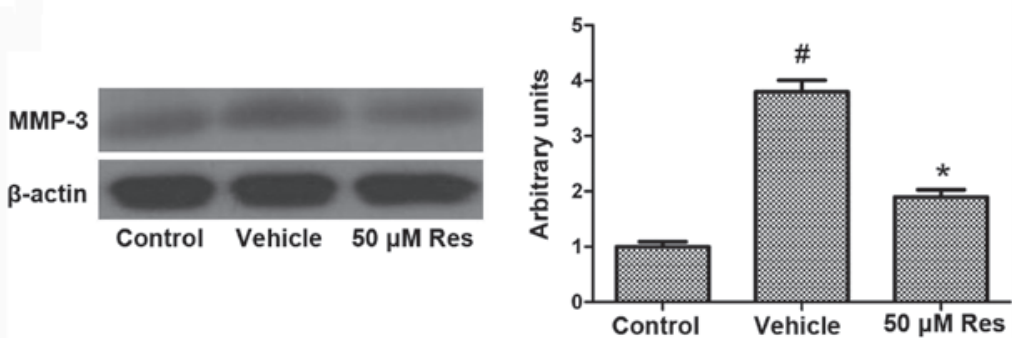

Figure 5. Resveratrol (Res) inhibits oxygen-glucose deprivation (OGD)-induced matrix metalloproteinase-3 (MMP-3) expression. (A) Relative expression of $M M P-3$, assessed by RT-PCR, shows that Res treatment $(50 \mu \mathrm{M})$ significantly reduced the OGD-induced expression of $M M P-3$. (B) Western blots and corresponding quantification data show similar results at the proteinlevel. ${ }^{\prime \prime} \mathrm{P}<0.05$ vs. control (no OGD); ${ }^{*} \mathrm{P}<0.05$ vs. vehicle (OGD + dimethylsulfoxide). 
A

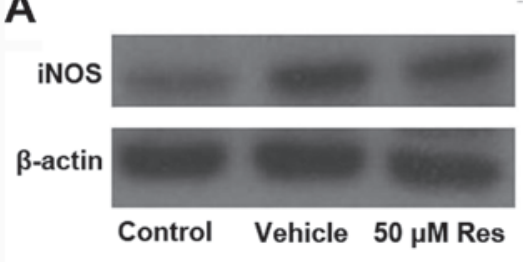

B

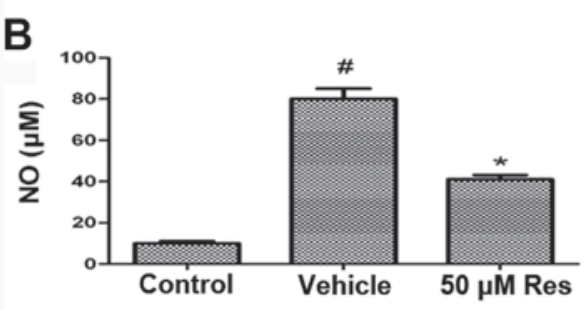

C

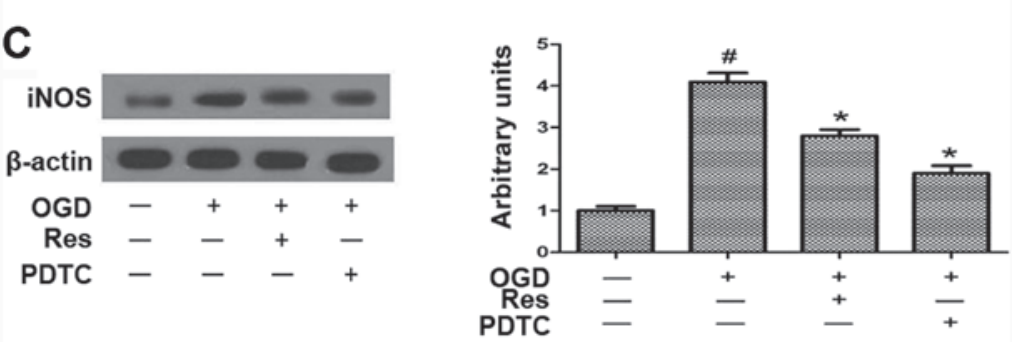

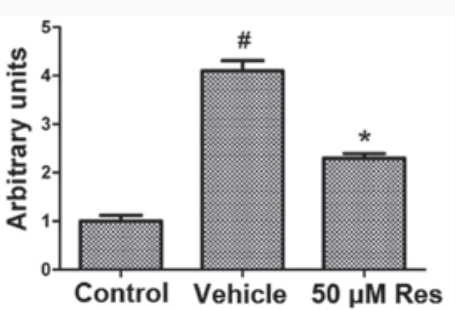

Control Vehicle $50 \mu \mathrm{M}$ Res

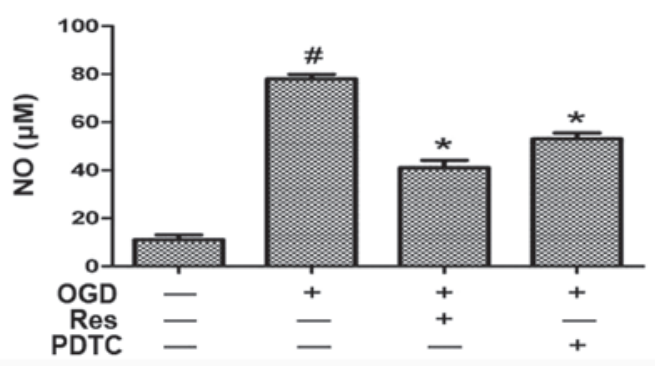

Figure 6. Res inhibits oxygen-glucose deprivation (OGD)-induced inducible NO synthase (iNOS) and nitric oxide (NO) production via nuclear factor (NF)- $\mathrm{BB}$ Primary cortical cells were exposed to OGD, followed by reoxygenation to simulate transient ischemia-reperfusion injury. Res (50 $\mu \mathrm{M})$ was added into the culture medium during transient ischemia in the presence or absence of $10 \mu \mathrm{M}$ pyrrolidine dithiocarbamate (PDTC). (A) Effect of Res on OGD-induced iNOS protein expression, assessed by western blot. (B) Effect of Res on the level of OGD-induced NO, assessed by the Griess assay. (C) Effect of PDTC on the OGD-induced iNOS and NO levels. "P<0.05 vs. control (no OGD); "P<0.05 vs. vehicle (OGD. + dimethylsulfoxide).

that Res achieves its anti-apoptotic effects through canonical apoptosis signaling pathways.

Res inhibits $O G D$-induced $N F-\kappa B$ expression. The expression of MMP-3 is regulated by the transcription factor $N F-\kappa B$. $\mathrm{NF}-\kappa \mathrm{B}$ is an ubiquitous transcription factor that resides in the cytoplasm but, when activated, is translocated to the nucleus, where it induces gene transcription. The activated $\mathrm{NF}-\kappa \mathrm{B}$ induces the expression of $>400$ genes, some of which are intimately involved in regulation of apoptosis, proliferation and inflammation. Hence, we examined whether Res can modulate OGD-induced expression of NF- $\kappa \mathrm{B}$. As shown in Fig. 4, OGD induced the expression of $\mathrm{NF}-\kappa \mathrm{B}$, while Res significantly inhibited its expression.

Effect of Res on the expression of MMP-3. To further investigate the mechanisms of Res-mediated neuroprotection, we studied its effect on MMP-3 expression. In both RT-PCR and western blot analyses, the exposure of cells to OGD significantly induced the expression of MMP-3 compared to the control cells, while Res treatment inhibited the OGD-induced expression of MMP-3 (Fig. 5). The level of the housekeeping protein $\beta$-actin remained unaffected.

Res attenuates $O G D$-induced $i N O S$ and NO production via $N F-\kappa B$. Excessive ROS production leads to activation of the transcription factor $\mathrm{NF}-\kappa \mathrm{B}$, which is associated with cell death during cerebral ischemia (28). OGD, excessive ROS production or glutamate toxicity induce iNOS expression $(29,30)$. We evaluated the expression of iNOS by western blot analysis, which showed that OGD increases the iNOS level compared to the control, and that this effect is reversed by treatment with $50 \mu \mathrm{M}$ Res (Fig. 6A). NO is a signaling molecule that regulates numerous biological processes in the nervous system, including neurotransmitter release, plasticity, and apoptosis, and can modulate the biological activity of numerous proteins, including MMPs. Cerebral ischemia and reperfusion injury result in nitrosative stress and hence the production of NO (11). OGD increased the NO level compared to the control, and Res treatment reversed 

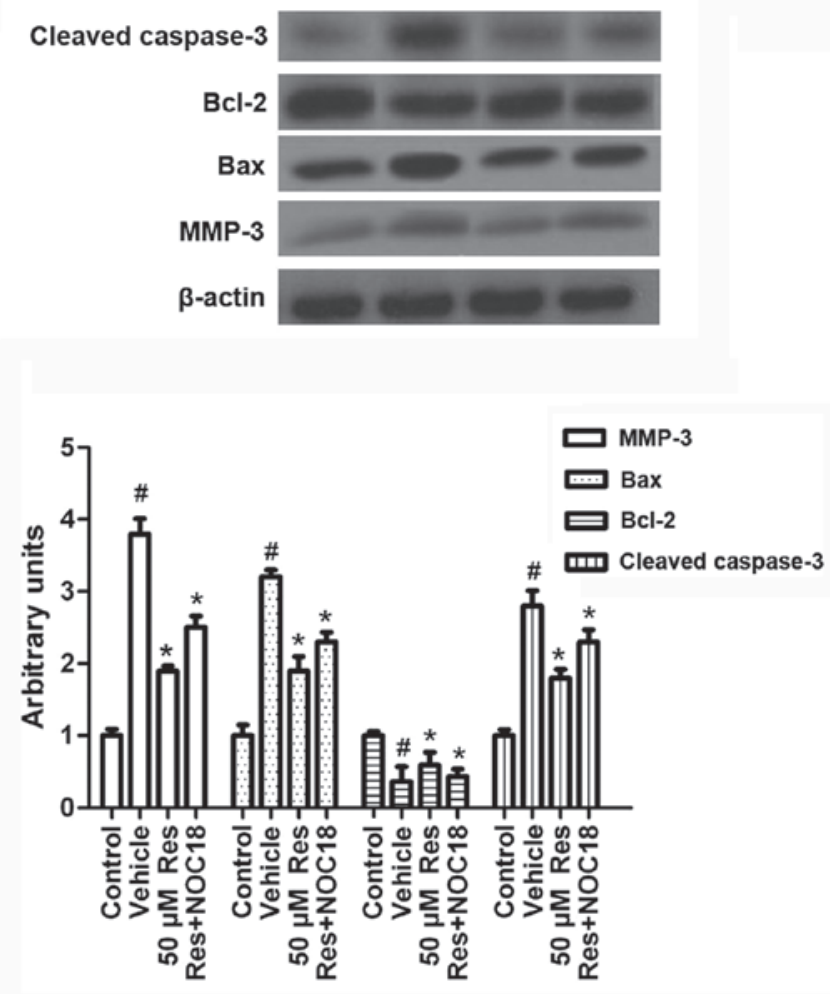

Figure 7. Resveratrol (Res) inhibits oxygen-glucose deprivation (OGD)-induced matrix metalloproteinase-3 (MMP-3) expression by affecting the levels of NO synthase (iNOS)/nitric oxide (NO). Primary cortical cells were exposed to OGD, followed by reoxygenation to simulate transient ischemia. Res $(50 \mu \mathrm{M})$ was added into the culture medium during transient ischemia in the presence or absence of $500 \mu \mathrm{M}$ NOC-18. ${ }^{\prime \prime} \mathrm{P}<0.05 \mathrm{vs}$. control (no OGD); ${ }^{*} \mathrm{P}<0.05$ vs. vehicle (OGD + dimethylsulfoxide).

this effect (Fig. 6B). To investigate whether Res attenuates OGD-induced iNOS and NO production via affecting the expression of NF- $\kappa B$, cells were pretreated with the NF- $\kappa B$ inhibitor PDTC 15 min prior to Res treatment. PDTC treatment reduced OGD-induced iNOS and NO expression, similar to the effect of Res (Fig. 6C). This result suggests that Res inhibits iNOS and NO expression via inhibiting the NF- $\kappa \mathrm{B}$ expression.

Res inhibits OGD-induced MMP-3 expression and cell apoptosis via iNOS/NO. To investigate the mechanism by which Res regulates OGD-induced cell apoptosis, we studied the exprerssion of apoptosis-related molecules in the presence of Res and NOC-18. Cells were treated with NOC-18 $(500 \mu \mathrm{M})$ during Res treatment $(50 \mu \mathrm{M})$. As shown in Fig. 7, supplementing NO via NOC-18 addition partly reversed the effect of Res on MMP-3, Bax, Bcl-2 and activated caspase-3 expression. This suggests that Res inhibits MMP-3 expression and cell apoptosis via iNOS/NO.

\section{Discussion}

This study shows for the first time that Res can protect neurons from cell apoptosis induced by OGD via a mechanism that involves NF- $\mathrm{kB}-\mathrm{iNOS} / \mathrm{NO}$ and the modulation of the expression of MMP-3.
Stroke causes brain injury in millions of people worldwide each year. Although it is well known that ischemia causes cellular damage, the underlying mechanism is not fully understood, and there is currently no approved therapy that can reduce infarction size or neurological disability $(31,32)$.

Cerebral ischemia-reperfusion injury results in cell destruction, with MMPs being the major proteases involved in cell damage in the ischemic tissue (14). MMPs are upregulated in permanent and transient ischemia. These proteins attack the extracellular matrix around the blood vessels, and facilitate cell death by attacking the matrix enveloping the neurons. A number of studies have provided evidence that the activation of MMPs leads to the proteolytic breakdown of the BBB during cerebral ischemia and reperfusion injury (33-35). A role for MMPs has also been suggested in the pathogenesis of both acute and chronic neurodegenerative disorders such as stroke (11). Immunohistochemical examinations of ischemic tissues in the rat brain revealed the expression of MMP-3 in microglia and neurons (36,37). A key approach in the development of therapy for stroke may be the interference with apoptotic signaling. In this context, a potential target is MMP-3, which participates in apoptotic signaling and the expression of which is specifically increased under cell stress conditions $(17,18)$. It has been reported that an antioxidant system that has a neuroprotective effect in ischemic brain injury is involved in neuronal apoptosis of vulnerable neurons in the cortex and the hippocampus during early reperfusion $(38,39)$.

In the present study, we showed that OGD insult causes a marked increase in the expression of MMP-3 at both the mRNA and the protein level, and in the percentage of apoptotic cells. Res, a natural phytoalexin that has anticancer, neuroprotective and anti-inflammatory effects, can reverse OGD-induced MMP-3 expression and cell apoptosis.

The transcriptional factor NF- $\mathrm{KB}$ is one of the most critical intracellular signaling molecules that regulates the expression of genes encoding, among others, MMPs and iNOS (40). Res can inhibit the activation of NF- $\mathrm{KB}$ and thus downregulate NF- $\kappa B$-regulated pro-inflammatory proteins such as MMP-9 and MMP-3 in osteoarthritis $(19,41)$. Res is a polyphenol with pleiotropic effects, which include the reduction of oxidative stress and increased vascular NO production (42). Whether Res can inhibit the expression of NF- $\mathrm{kB}$ and regulate downstream genes such as MMP-3 and iNOS has not been clearly shown to date. In this study, we found that Res can inhibit the OGD-induced expression of NF- $\kappa \mathrm{B}$, iNOS and MMP-3.

In conclusion, OGD induces apoptosis through canonical apoptosis signaling and by regulating the expression of MMP-3; Res can reverse OGD-induced MMP-3 expression and cell apoptosis via the NF-kB-iNOS/NO pathway. The results reported here further support the idea that Res, which is naturally found in red wine and other products, exerts neuroprotective effects in experimental models of cerebral ischemia. Thus, Res may be considered a candidate agent for the treatment of stroke.

\section{Acknowledgements}

The current study was supported by a grant from the National Natural Science Fund of China (no. 30901553). 


\section{References}

1. Hallenbeck JM and Dutka AJ: Background review and current concepts of reperfusion injury. Arch Neurol 47: 1245-1254, 1990

2. Magnoni S, Baker A, George SJ, Duncan WC, Kerr LE, McCulloch J and Horsburgh K: Differential alterations in the expression and activity of matrix metalloproteinases 2 and 9 after transient cerebral ischemia in mice. Neurobiol Dis 17: 188-197, 2004.

3. Oguro K, Jover T, Tanaka H, Lin Y, Kojima T, Oguro N, Grooms SY, Bennett MV and Zukin RS: Global ischemia-induced increases in the gap junctional proteins connexin $32(\mathrm{Cx} 32)$ and Cx36 in hippocampus and enhanced vulnerability of Cx32 knock-out mice. J Neurosci 21: 7534-7542, 2001.

4. Amantea D, Nappi G, Bernardi G, Bagetta G and Corasaniti MT: Post-ischemic brain damage: pathophysiology and role of inflammatory mediators. FEBS J 276: 13-26, 2009.

5. Choi JS, Kim SJ, Shin JA, Lee KE and Park EM: Effects of estrogen on temporal expressions of IL-1beta and IL-1ra in rat organotypic hippocampal slices exposed to oxygen-glucose deprivation. Neurosci Lett 438: 233-237, 2008.

6. Fekete A, Vizi ES, Kovács KJ, Lendvai B and Zelles T: Layer-specific differences in reactive oxygen species levels after oxygen-glucose deprivation in acute hippocampal slices. Free Radic Biol Med 44: 1010-1022, 2008

7. Kiewert C, Kumar V, Hildmann O, Hartmann J, Hillert M and Klein J: Role of glycine receptors and glycine release for the neuroprotective activity of bilobalide. Brain Res 1201: 143-150, 2008.

8. Rosenberg GA: Matrix metalloproteinases in neuroinflammation. Glia 39: 279-291, 2002.

9. Gurney KJ, Estrada EY and Rosenberg GA: Blood-brain barrier disruption by stromelysin-1 facilitates neutrophil infiltration in neuroinflammation. Neurobiol Dis 23: 87-96, 2006.

10. Garcia AJ, Tom C, Guemes M, Polanco G, Mayorga ME, Wend K, Miranda-Carboni GA and Krum SA: ER $\alpha$ signaling regulates MMP3 expression to induce FasL cleavage and osteoclast apoptosis. J Bone Miner Res 28: 283-290, 2013.

11. Gu Z, Kaul M, Yan B, Kridel SJ, Cui J, Strongin A, Smith JW, Liddington RC and Lipton SA: S-nitrosylation of matrix metalloproteinases: signaling pathway to neuronal cell death Science 297: 1186-1190, 2002.

12. Rosenberg GA, Cunningham LA, Wallace J, Alexander S, Estrada EY, Grossetete M, Razhagi A, Miller K and Gearing A: Immunohistochemistry of matrix metalloproteinases in reperfusion injury to rat brain: activation of MMP-9 linked to stromelysin-1 and microglia in cell cultures. Brain Res 893 : 104-112, 2001.

13. Wetzel M, Rosenberg GA and Cunningham LA: Tissue inhibitor of metalloproteinases-3 and matrix metalloproteinase-3 regulate neuronal sensitivity to doxorubicin-induced apoptosis. Eur J Neurosci 18: 1050-1060, 2003.

14. Cheng Z, He W, Zhou X, Lv Q, Xu X, Yang S, Zhao C and Guo L: Cordycepin protects against cerebral ischemia/reperfusion injury in vivo and in vitro. Eur J Pharmacol 664: 20-28, 2011.

15. Walker EJ and Rosenberg GA: TIMP-3 and MMP-3 contribute to delayed inflammation and hippocampal neuronal death following global ischemia. Exp Neurol 216: 122-131, 2009.

16. Kim YS, Kim SS, Cho JJ, Choi DH, Hwang O, Shin DH, Chun HS, Beal MF and Joh TH: Matrix metalloproteinase-3: a novel signaling proteinase from apoptotic neuronal cells that activates microglia. J Neurosci 25: 3701-3711, 2005.

17. Choi DH, Kim EM, Son HJ, Joh TH, Kim YS, Kim D, Flint Beal M and Hwang O: A novel intracellular role of matrix metalloproteinase-3 during apoptosis of dopaminergic cells. J Neurochem 106: 405-415, 2008.

18. Kim EM, Shin EJ, Choi JH, Son HJ, Park IS, Joh TH and Hwang O: Matrix metalloproteinase-3 is increased and participates in neuronal apoptotic signaling downstream of caspase-12 during endoplasmic reticulum stress. J Biol Chem 285: 16444-16452, 2010

19. Csaki C, Mobasheri A and Shakibaei M: Synergistic chondroprotective effects of curcumin and resveratrol in human articular chondrocytes: inhibition of IL- $1 \beta$-induced NF- $\kappa \mathrm{B}$-mediated inflammation and apoptosis. Arthritis Res Ther 11: R165, 2009.

20. Celotti E, Ferrarini R, Zironi R and Conte LS: Resveratrol content of some wines obtained from dried Valpolicella grapes: Recioto and Amarone. J Chromatogr A 730: 47-52, 1996.

21. Pany S, Majhi A and Das J: PKC activation by resveratrol derivatives with unsaturated aliphatic chain. PLoS One 7: e52888, 2012
22. Das J, Pany S and Majhi A: Chemical modifications of resveratrol for improved protein kinase C alpha activity. Bioorg Med Chem 19: 5321-5333, 2011.

23. Carrizzo A, Puca A, Damato A, Marino M, Franco E, Pompeo F, Traficante A, Civitillo F, Santini L, Trimarco V and Vecchione C: Resveratrol improves vascular function in patients with hypertension and dyslipidemia by modulating NO metabolism. Hypertension 62: 359-366, 2013.

24. Kesherwani V, Atif F, Yousuf S and Agrawal SK: Resveratrol protects spinal cord dorsal column from hypoxic injury by activating Nrf-2. Neuroscience 241: 80-88, 2013.

25. Wang Q, Xu J, Rottinghaus GE, Simonyi A, Lubahn D, Sun GY and Sun AY: Resveratrol protects against global cerebral ischemic injury in gerbils. Brain Res 958: 439-447, 2002.

26. Gao D, Zhang X, Jiang X, Peng Y, Huang W, Cheng G and Song L: Resveratrol reduces the elevated level of MMP-9 induced by cerebral ischemia-reperfusion in mice. Life Sci 78: 2564-2570, 2006.

27. Tauskela JS, Comas T, Hewitt K, Monette R, Paris J, Hogan M and Morley P: Cross-tolerance to otherwise lethal $\mathrm{N}$-methyl-D-aspartate and oxygen-glucose deprivation in preconditioned cortical cultures. Neuroscience 107: 571-584, 2001.

28. Dal-Cim T,Ludka FK, Martins WC, Reginato C, Parada E, Egea J, López MG and Tasca CI: Guanosine controls inflammatory pathways to afford neuroprotection of hippocampal slices under oxygen and glucose deprivation conditions. J Neurochem 126: 437-450, 2013.

29. Martín-de-Saavedra MD, del Barrio L, Cañas N, Egea J,Lorrio S, Montell E, Vergés J, García AG and López MG: Chondroitin sulfate reduces cell death of rat hippocampal slices subjected to oxygen and glucose deprivation by inhibiting $\mathrm{p} 38, \mathrm{NF} \mathrm{KB}$ and iNOS. Neurochem Int 58: 676-683, 2011.

30. Molz S, Dal-Cim T, Budni J, Martín-de-Saavedra MD, Egea J, Romero A, del Barrio L, Rodrigues AL, López MG and Tasca CI: Neuroprotective effect of guanosine against glutamateinduced cell death in rat hippocampal slices is mediated by the phosphatidylinositol-3 kinase/Akt/ glycogen synthase kinase $3 \beta$ pathway activation and inducible nitric oxide synthase inhibition. J Neurosci Res 89: 1400-1408, 2011.

31. Schaller B and Graf R: Cerebral ischemia and reperfusion: the pathophysiologic concept as a basis for clinical therapy. J Cereb Blood Flow Metab 24: 351-371, 2004.

32. Moskowitz MA, Lo EH and Iadecola C: The science of stroke: mechanisms in search of treatments. Neuron 67: 181-198, 2010.

33. Aoki T, Sumii T, Mori T, Wang X and Lo EH: Blood-brain barrier disruption and matrix metalloproteinase-9 expression during reperfusion injury: mechanical versus embolic focal ischemia in spontaneously hypertensive rats. Stroke 33: 2711-2717, 2002.

34. Maier CM, Hsieh L, Yu F, Bracci P and Chan PH: Matrix metalloproteinase-9 and myeloperoxidase expression: quantitative analysis by antigen immunohistochemistry in a model of transient focal cerebral ischemia. Stroke 35: 1169-1174, 2004.

35. Pfefferkorn T and Rosenberg GA: Closure of the blood-brain barrier by matrix metalloproteinase inhibition reduces rtPA-mediated mortality in cerebral ischemia with delayed reperfusion. Stroke 34: 2025-2030, 2003.

36. Cunningham LA, Wetzel M and Rosenberg GA: Multiple roles for MMPs and TIMPs in cerebral ischemia. Glia 50: 329-339, 2005.

37. Dzwonek J, Rylski M and Kaczmarek L: Matrix metalloproteinases and their endogenous inhibitors in neuronal physiology of the adult brain. FEBS Lett 567: 129-135, 2004

38. Fujimura M, Tominaga T and Chan PH: Neuroprotective effect of an antioxidant in ischemic brain injury: involvement of neuronal apoptosis. Neurocrit Care 2: 59-66, 2005.

39. Krause GS, White BC, Aust SD, Nayini NR and Kumar K Brain cell death following ischemia and reperfusion: a proposed biochemical sequence. Crit Care Med 16: 714-726, 1988.

40. Marcu KB, Otero M, Olivotto E, Borzi RM and Goldring MB NF-kappaB signaling: multiple angles to target OA. Curr Drug Targets 11: 599-613, 2010.

41. Shakibaei M, Csaki C, Nebrich S and Mobasheri A: Resveratrol suppresses interleukin-1 $\beta$-induced inflammatory signaling and apoptosis in human articular chondrocytes: potential for use as a novel nutraceutical for the treatment of osteoarthritis. Biochem Pharmacol 76: 1426-1439, 2008.

42. Dolinsky VW, Chakrabarti S, Pereira TJ, et al: Resveratrol prevents hypertension and cardiac hypertrophy in hypertensive rats and mice. Biochim Biophys Acta 1832: 1723-1733, 2013. 